\title{
Powder Metallurgy Manufacturing of Carbon-Free Precipitation Hardened High Speed Steels
}

\author{
H. Danninger ${ }^{a}$, Ch. Harold ${ }^{a}$, Ch. Gierl $^{a}$, H. Ponemayr $^{b}$, M. Daxelmueller $^{c}$, \\ F. SIMANCIK ${ }^{d}$ AND K. IZDINSKY ${ }^{d}$ \\ ${ }^{a}$ Vienna University of Technology, A-1060 Wien, Austria \\ ${ }^{b}$ Boehler-Ybbstal Profil GmbH, A-3333 Boehlerwerk, Austria \\ ${ }^{c}$ Boehler Uddeholm Precision Strip GmbH, A-3333 Boehlerwerk, Austria \\ ${ }^{d}$ Institute of Materials and Machine Mechanics SAS, SK-83102 Bratislava, Slovakia
}

\begin{abstract}
Carbon-free steels of the type Fe-Co-(Mo, W) have been known for long to attain very high hardness levels through precipitation hardening. However, the classical ingot metallurgy route tended to result in brittle materials. Here it is shown that the powder metallurgy route through mixing of elemental powders, pressing and sintering results in materials with excellent combination of hardness and transverse rupture strength if the processing parameters are adjusted accordingly, in particular sintering and heat treatment being critical stages that should result in chemically homogeneous and fine-grained microstructure. If properly processed, these steel grades offer excellent red hardness since the hardening intermetallic phases are much less sensitive to overaging than the secondary carbides in standard high speed steels.
\end{abstract}

PACS numbers: 81.05. Bx, 81.40.--Z

\section{Introduction}

Tool steels are superior to other tool materials regarding manufacturing of tools, being available in a comparatively soft and machinable/workable fabrication state and in a hard, load resistant application state. The transition between both states is done by suitable heat treatment $[1,2]$. Thus, markedly more fabrication processes are feasible for tool steels than for inherently hard tool materials as e.g. hardmetals, cermets, or cutting ceramics. Tool steels are however sensitive to the thermal overloading, which results in softening of the material. Today, high alloy steel grades containing $\mathrm{W}, \mathrm{Mo}, \mathrm{V}$ and $\mathrm{Co}$, known as high speed steels (HSS), are available the hot hardness of which relies on several mechanisms [2, 3], the most prominent one being precipitation hardening by secondary carbides giving high hot hardness and cutting performance up to about $600^{\circ} \mathrm{C}$; at higher temperatures however rapid overaging of the precipitates results in loss of cutting performance.

Furthermore, the heat treatment of tool steels adversely affects the geometrical precision, resulting in distortion which can be corrected only by grinding. There are however other hardening mechanisms that involve more isothermal conditions during the actual hardening process. In precipitation strengthening, e.g. of $\mathrm{Al}$ alloys or maraging steels, quenching results in soft and ductile materials, and the required strength is attained during a virtually isothermal aging process, which results in dimensional changes that are well controllable.

A quite similar approach as with maraging steels has been tried very early by Köster et al. [4-6] who investi- gated carbon-free ferrous alloys Fe-Co-Mo and Fe-Co-W and found that these can be precipitation hardened by secondary $\mu$-phases $(\mathrm{Fe}, \mathrm{Co})_{7} \mathrm{Mo}_{6}$ and $(\mathrm{Fe}, \mathrm{Co})_{7} \mathrm{~W}_{6}$, respectively. They further found that these carbon-free alloys are comparatively soft in the as-quenched condition and obtain high hardness only during a heat treatment at moderate temperatures. It also showed that these alloys can attain hardness levels in the range of classical high speed steels but their tendency to overaging is markedly less pronounced than with standard high speed steel grades. In the 1960s, Geller et al. in Russia [7-9] carried out systematic investigations on different types of carbon-free steels of the basic type $\mathrm{Fe}-(\mathrm{Co}, \mathrm{Ni})-(\mathrm{W}, \mathrm{Mo})$. They claim that the hot hardness is related to the temperature of the ferrite-austenite transformation; the higher the temperature, the higher the hot hardness. Geller et al. reported that these tool materials are particularly well suitable for machining of Ti alloys, which are notoriously difficult to cut.

However, the materials obtained from 1930 to the 1970s exhibited low toughness, at least in part due to the ingot metallurgy production route [10]. Powder metallurgy was regarded as a possible solution already in the 1930s [11] but was not pursued further at that time. In the 1990s, Karpov et al. [12] used a powder metallurgy route for producing an Fe-Co-W-Mo alloy, the process sequence being co-reduction of the mixed oxides and then pressing and sintering of the co-reduced powder. Virtually full density was attained, and the hardness levels after precipitation hardening were up to 70 HRC. A similar, but simpler approach starting from elemental pow- 


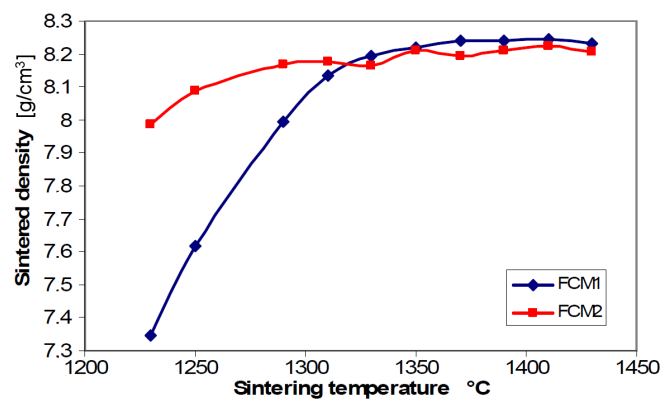

Fig. 1. Sintered density of FCM1 and FCM2 as a function of the sintering temperature. Compacted at $400 \mathrm{MPa}$, sintered for $120 \mathrm{~min}$ in $\mathrm{H}_{2}$.

ders is described in [13]. In the present work, further studies on this material are described, and it is shown that these carbon-free PM tool materials not only offer excellent hot hardness and cutting performance but are also particularly suited for precision tools.

\section{Experimental procedure}

Two material grades were investigated, designated FCM1 and FCM2, which had the compositions Fe$25 \%$ Co- $15 \%$ Mo (mass \%) and Fe-20\%Co-15\%Mo, respectively. The starting powders used were Carbonyl iron (BASF grade $\mathrm{CN}$ ), Co powder (Umex 5-M), and elemental Mo (Plansee, $<32 \mu \mathrm{m}$ ). The powders were dry blended for $60 \mathrm{~min}$ in a tumbling mixer and then uniaxially compacted at $400 \mathrm{MPa}$ under die wall lubrication to bars of $55 \times 10 \times 15$ and $100 \times 12 \times 15 \mathrm{~mm}$, respectively. The compacts were sintered in an electrically heated pushtype furnace with Mo heating elements (Degussa type Baby) at $1230-1400^{\circ} \mathrm{C}$ in flowing hydrogen of technical purity.

After sintering, the density was measured through water displacement, and then the bars were heated in flowing $\mathrm{N}_{2}$ and hot rolled in several passes, resulting in a total thickness reduction of about $50 \%$. For test specimens, flat rolling was done using die pressed specimens. If the preheating temperature was held within the optimum range, crack-free specimens could be obtained. After hot rolling, the bars were ground on all faces to result in rectangular specimens for 3-point bend tests. The bars were then solution treated in flowing nitrogen, oil quenched, and aged in $\mathrm{N}_{2}$ at varying temperatures. These bars were tested in 3-point bending. Metallographic and fractographic studies were done, as were TEM investigations. The Rockwell hardness was measured on the surfaces and in the cross section; there were however virtually no differences.

\section{Effect of the sintering temperature on density and as-sintered microstructure}

Sintering for $120 \mathrm{~min}$ in flowing $\mathrm{H}_{2}$ at temperatures ranging from 1230 to $1430^{\circ} \mathrm{C}$ resulted in density levels

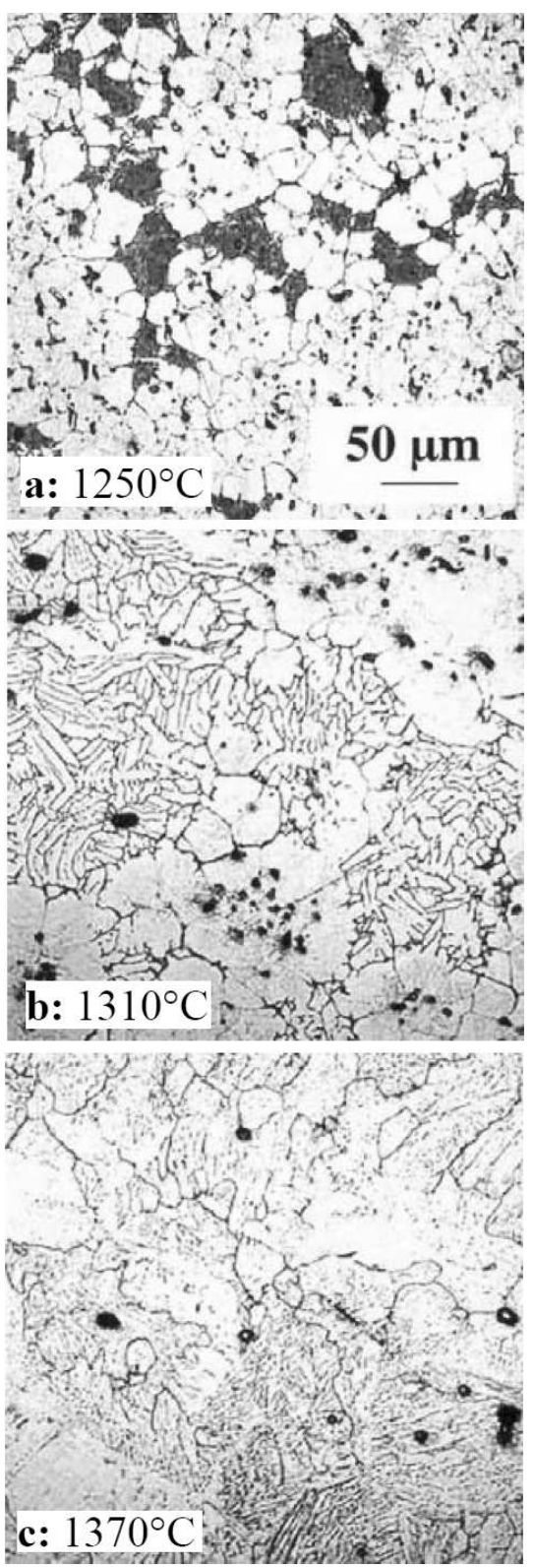

Fig. 2. Microstructure of FCM1 compacted at $400 \mathrm{MPa}$, sintered for $2 \mathrm{~h}$ in $\mathrm{H}_{2}$; (a) at $1250^{\circ} \mathrm{C}$, (b) at $1310{ }^{\circ} \mathrm{C},(\mathrm{c})$ at $1370{ }^{\circ} \mathrm{C}$.

as shown in Fig. 1 and in as-sintered microstructures depicted in Fig. 2 and 3 (etched $\mathrm{FeCl}_{3}$, repolished).

$>$ From Fig. 1 it is clearly visible that the higher Co variant FCM1 requires significantly higher temperatures to attain virtually full density that FCM2, about $1370^{\circ} \mathrm{C}$ being the threshold temperature. The same holds also for the microstructural homogeneity, as discernible in the micrographs from which is can be seen that in the case of FCM1 (Fig. 2), heterogeneous microstructures are visible up to at least $1310^{\circ} \mathrm{C}$, and also pore clusters are related to the heterogeneities - in fact to Co-rich areas - while with FCM2 reasonably homogeneous microstructures are obtained already after sintering at $1290^{\circ} \mathrm{C}$. 


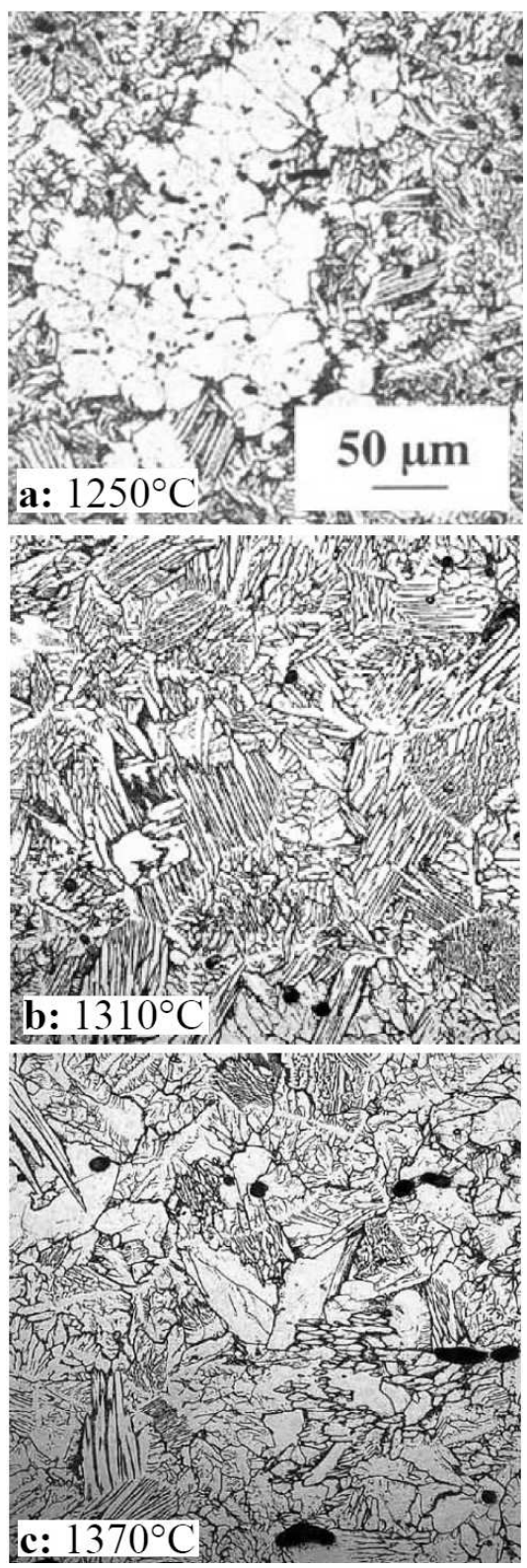

Fig. 3. Microstructure of FCM2 compacted at $400 \mathrm{MPa}$, sintered for $2 \mathrm{~h}$ in $\mathrm{H}_{2}$; (a) at $1250^{\circ} \mathrm{C}$, (b) at $1310{ }^{\circ} \mathrm{C}$, (c) at $1370{ }^{\circ} \mathrm{C}$

\section{Effect of the sintering temperature on the as-heat treated materials}

The effect of the sintering temperature, in particular of microstructural homogeneity, can be expected to be more pronounced in the fully hardened $(>60 \mathrm{HRC})$ state that in the relatively soft (typically $<40 \mathrm{HRC}$ ) as-sintered one [13]. The residual porosity, in contrast, should not play a major role since, as stated above, the steels are hot worked to full density after sintering. Therefore, sintered specimens were fully densified by hot rolling, then they were solution treated in high purity $\mathrm{N}_{2}$ for $30 \mathrm{~min}$ at $1150^{\circ} \mathrm{C}$ and $1200^{\circ} \mathrm{C}$, respectively, since it had been found

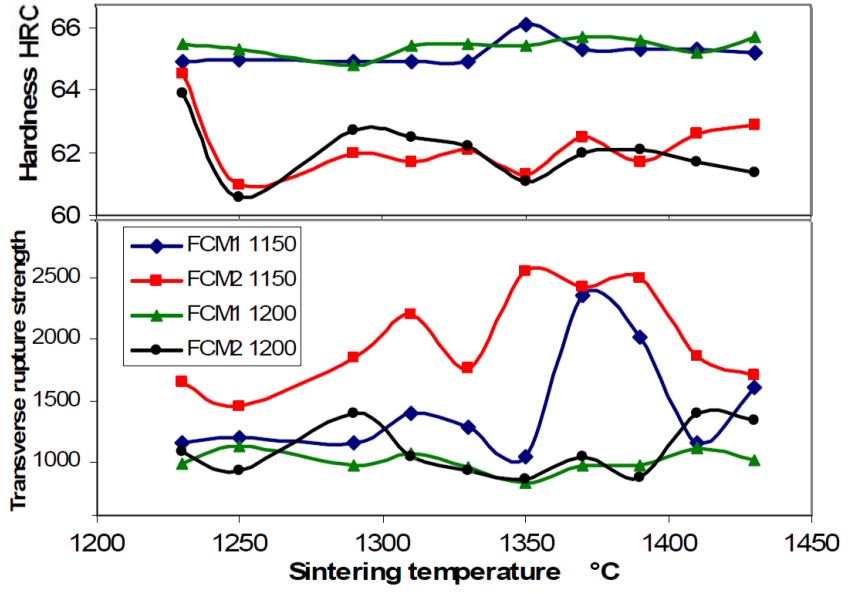

Fig. 4. Properties of FCM1 and FCM2, heat treated.

that this treatment has a major impact on the strength at least with FCM1 [13]. After oil quenching, peak aging was done for $60 \mathrm{~min}$ at $600{ }^{\circ} \mathrm{C}$, as given in [13]. The results of hardness HRC and transverse rupture strength (TRS) measurements are plotted in Figs. 4a,b. Metallographic sections were prepared, Nital etching being done (Figs. 5, 6).

As can be seen, the hardness level attained with FCM1 is generally higher than with FCM2, indicating that not only the precipitation of the secondary $\mu$-phases but also solid solution strengthening by $\mathrm{Co}$ is highly effective towards the hardness. The effect of the solution treatment temperature on the hardness is virtually negligible. This is completely different when observing the transverse rupture strength: here for both materials solution treatment at $1200{ }^{\circ} \mathrm{C}$ results in relatively low TRS levels of about $1000 \mathrm{MPa}$ for all sintering temperatures. Solution annealing at $1150{ }^{\circ} \mathrm{C}$, in contrast, enables attaining TRS values of up to $2500 \mathrm{MPa}$ in the case of optimum sintering, the interval for the sintering temperature being rather narrow for FCM1 - $1370-1390{ }^{\circ} \mathrm{C}$ - but wider for FCM2, which can be attributed to the more rapid homogenization in the latter material.

The very regular microstructures of the heat treated specimens, performed for both materials sintered at $1370^{\circ} \mathrm{C}$ revealed the slower homogenization of FCM1. For both steel grades this temperature seems to be the optimum, although exact control of this temperature is less critical for FCM2.

\section{Influence of the aging temperature}

The previous experiments have shown that the maximum hardness levels are somewhat different for the two materials investigated, higher Co content resulting in higher hardness. However, it might be assumed that the heat treatment applied here, in particular the aging temperature, is more appropriate for FCM1 than for FCM2.

In order to estimate the hardness levels attainable by both materials in more detail and in particular the 


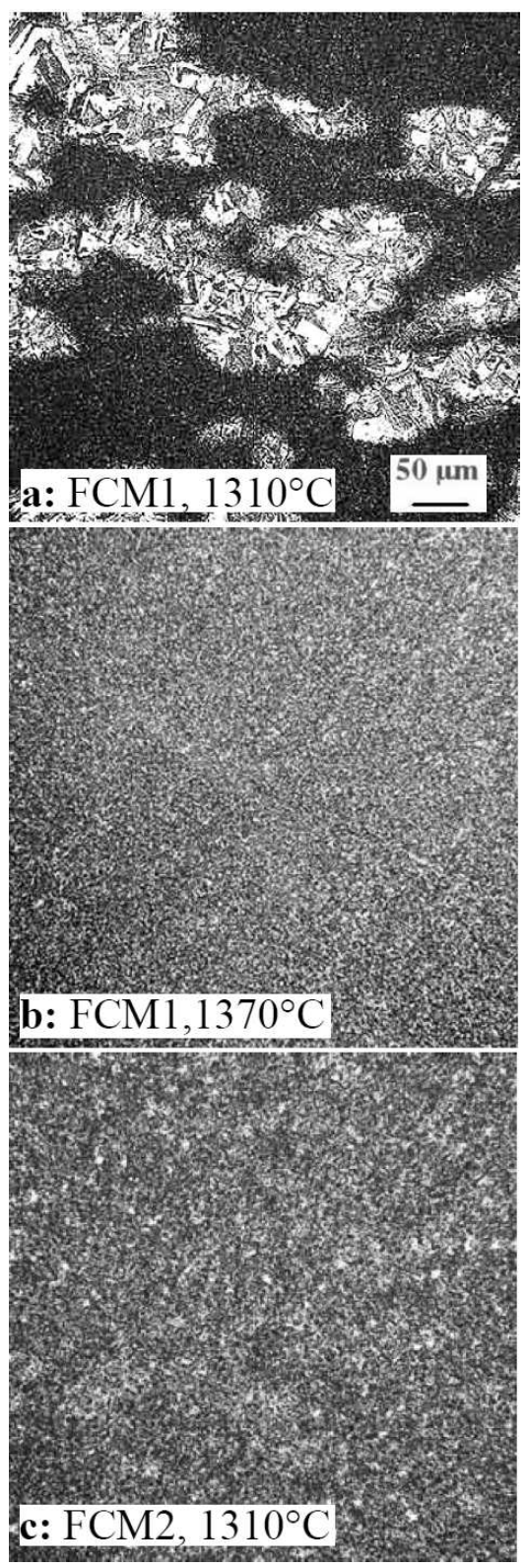

Fig. 5. Microstructures of FCM1/2 compacted at $400 \mathrm{MPa}$, sintered for $2 \mathrm{~h}$ in $\mathrm{H}_{2}$, heat treated for $30 \mathrm{~min}$ $1150{ }^{\circ} \mathrm{C} /$ oil quenched $/ 60$ min $600{ }^{\circ} \mathrm{C}$; (a) at $1310^{\circ} \mathrm{C}$, (b) at $1370^{\circ} \mathrm{C}$, (c) at $1310^{\circ} \mathrm{C}$.

overaging behaviour, specimens sintered for $120 \mathrm{~min}$ at $1370{ }^{\circ} \mathrm{C}$ and then hot rolled to full density were solution treated at $1150{ }^{\circ} \mathrm{C}$ for $30 \mathrm{~min}$, oil quenched and artificially aged for $60 \mathrm{~min}$ at different temperatures in high purity $\mathrm{N}_{2}$. The hardness levels attained as a function of the aging temperature are shown in Fig. 6 .

As can be clearly seen, both materials exhibit the typical aging response of precipitation strengthened materials, with relatively low as-quenched hardness, in the supersaturated state. Only at $T>400^{\circ} \mathrm{C}$ precipitates are formed, and the hardness significantly increases within a fairly narrow temperature interval, slightly earlier in

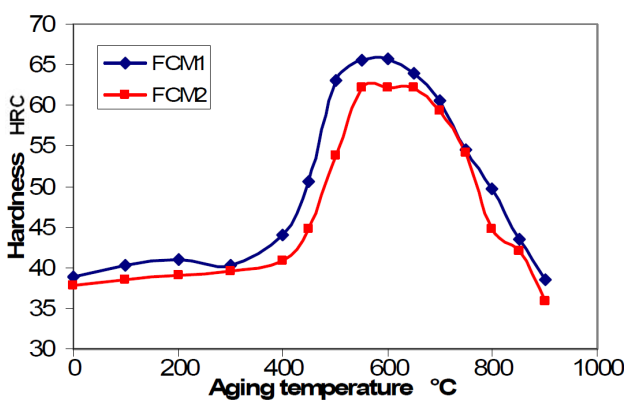

Fig. 6. Hardness as a function of the aging temperature. Sintered at $1370{ }^{\circ} \mathrm{C}$, hot rolled, solution treated at $1150^{\circ} \mathrm{C}$, oil quenched.

the case of the grade with the higher Co content. The maximum hardness is attained when aging is done at $550-650^{\circ} \mathrm{C}$. Here, the difference between the two grades is evident: the addition of $25 \%$ Co results in about 66 HRC, i.e. the typical hardness levels of high speed steels, while the grade with $20 \%$ Co attains about $62 \mathrm{HRC}$, which is common e.g. with cold work tool steels. In any case, the heat treatment for maximum hardness is virtually the same for both steel grades; the lower Co grade for FCM2 seems to require slightly higher temperatures but in any case aging at $600^{\circ} \mathrm{C}$ is optimal for both materials.

At higher temperatures the hardness drops, but the overaging process is much slower than known from carbidic HSS, even after $60 \mathrm{~min}$ at $700^{\circ} \mathrm{C}$ still hardness levels of about $60 \mathrm{HRC}$ being obtained. With regard to overaging, there is not much difference between the two steel grades, which indicates that the higher hardness of the grade FCM1 is mostly due to more pronounced solid solution strengthening by Co [3] while the effect of the secondary precipitates is similar for both grades. The aging response as a function of time has been shown e.g. in [13]; here it was found that the aging time plays a major role only in the intermediate range of about $500{ }^{\circ} \mathrm{C}$; at temperatures about $600^{\circ} \mathrm{C}$, full hardness is attained after a few minutes.

\section{Identification of the strengthening phases}

According to Köster et al. [4-6], the precipitation strengthening is caused by formation of secondary $\mu$-phases. This phase was previously defined as $\mathrm{Fe}_{3} \mathrm{Mo}_{2}$; the formula given today is $M_{7} \mathrm{Mo}_{6}$, i.e. in the present case we shall expect the composition $(\mathrm{Fe}, \mathrm{Co})_{7} \mathrm{Mo}_{6}$.

TEM investigations were carried out on the material FCM1 to reveal the structure and the morphology of the intermetallic phases present. In Fig. 7a, a typical primary intermetallic phase is shown; the rather rounded shape, in part surely a consequence of superficial dissolution during the solution treatment, can be seen which shape is even visible in the optical micrographs - as well as the twinning within the particle. Electron diffraction (Fig. 7b) confirmed that the particle is formed 

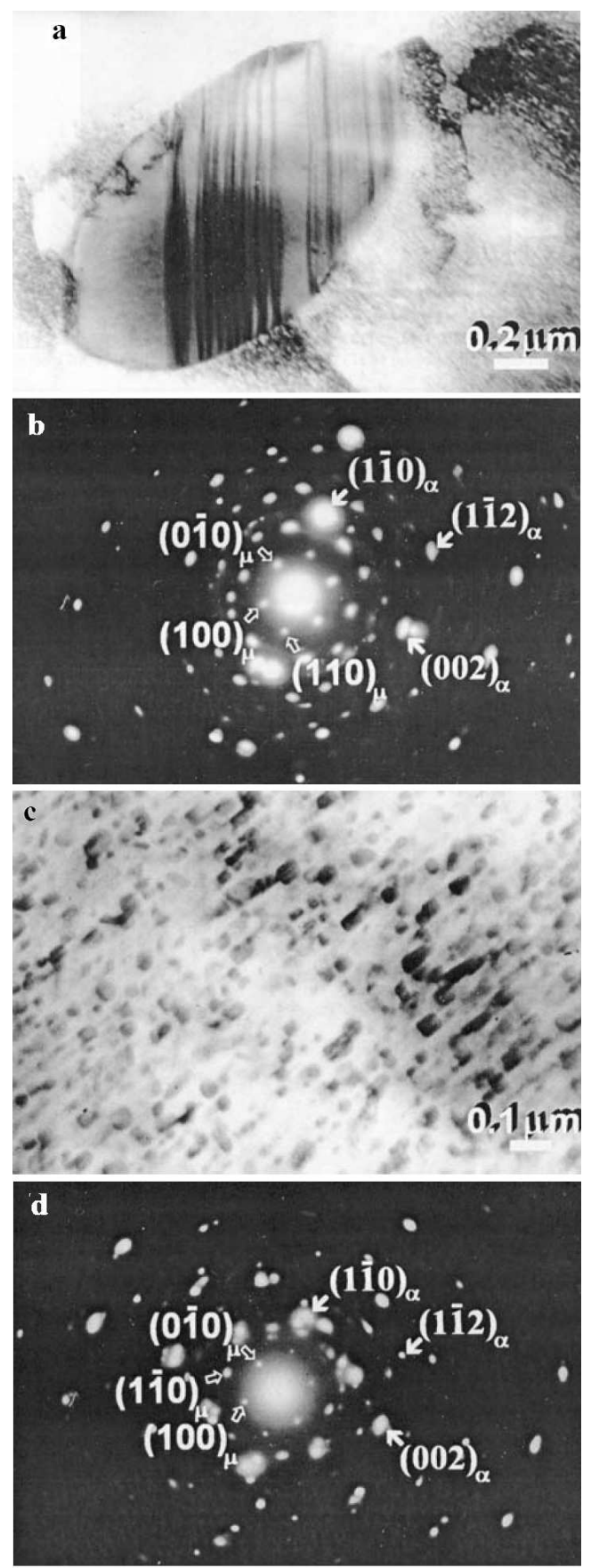

Fig. 7. Transmission electron images of FCM1, solution treated at $1200^{\circ} \mathrm{C}$, aged to peak hardness at $600^{\circ} \mathrm{C}$. (a) Primary $\mu$-phase; bright field image. (b) Primary $\mu$-phase; electron diffraction pattern. (b) Secondary precipitates; bright field image. (c) Secondary precipitates; electron diffraction pattern.

by the $\mu$-phase $(\mathrm{Fe}, \mathrm{Co})_{7} \mathrm{Mo}_{6}$. In Fig. $7 \mathrm{c}$, secondary precipitates are shown; a rather blocky morphology is evident. This shape can be assumed to make these precipitates superior to such intermetallic phases that tend to appear in lamellar shape, thus causing internal notch effects. Also here, the electron diffraction pattern (Fig. 7d) confirmed the precipitates to be the $\mu$-phase. Gener- ally it can thus be stated that the materials consist of a ferritic matrix, Fe-Co with some Mo, and two variants of intermetallic phase with widely different sizes; the primary intermetallic phases, with diameters in the $\mu \mathrm{m}$ size range, and the secondary precipitates generated during the aging process. However, both are formed by the $\mu$-phase $(\mathrm{Fe}, \mathrm{Co})_{7} \mathrm{Mo}_{6}$, no other intermetallic phases being present.

\section{Discussion}

As described above, the sintering, especially the homogenization, behaviour of the steels is markedly different in FCM1 and to FCM2, the latter exhibiting faster densification and homogenization. The reason for this difference can be derived from the phase diagram Fe-Co-Mo as given by Raynor and Rivlin [14]: the composition of FCM1 (Fe-25\%Co-15\%Mo) results in formation of homogeneous austenite both at $1200^{\circ} \mathrm{C}$ and $1300^{\circ} \mathrm{C}$ while that of FCM2 (Fe-20\%Co-15\%Mo) is in the two-phase field $\alpha+\gamma$, i.e. also ferrite is present during the isothermal sintering, and it is well known that sintering of iron and steels at least in part in the $\alpha$ range strongly promotes both densification and homogenization [15].

Heat treatment of the two steel grades is done by solution annealing, quenching, and aging, following the classical pattern for precipitation hardened materials. The heat treatment response thus is not like that of carbidic tool steels but rather similar to maraging steels or $\mathrm{Al}$ alloys, the materials being fairly soft and machinable as-quenched, obtaining maximum hardness during isothermal aging. The hardness is caused by the $\mu$-phase $(\mathrm{Fe}, \mathrm{Co})_{7} \mathrm{Mo}_{6}$, in part forming inclusions of $1-3 \mu \mathrm{m}$ diameter, but the full hardening is caused by secondary precipitates of the same $\mu$-phase that are in the $\mathrm{nm}$ range, which is clearly indicated by TEM studies. Recently, the precipitation mechanism has been studied in detail by Eidenberger et al. [16].

There is a very strong effect of the solution annealing temperature on the properties. The reason can be found in the tendency to grain coarsening (as described in detail in [13]): if the $\mu \mathrm{m}$ size phases present in the material are completely dissolved - or at least if the volume fraction decreases below a given threshold - their grain growth inhibiting effect is lost, and the grains coarsen, as known also from classical high speed steels, with resulting adverse effect on the strength. According to Raynor and Rivlin [14], $\mu$-phase is stable in FCM1 and FCM2 at $1100^{\circ} \mathrm{C}$ but not at $1200^{\circ} \mathrm{C}$. It has to be ensured, by selection of the correct solution annealing temperature, that there is always some part of the intermetallic phase present as $\mu \mathrm{m}$-size globules that are able to stabilize the grains. This of course means that the Mo in these phases is no more available for secondary hardening, but as indicated by Fig. 4a, the effect of these additional secondary phases on the hardness is negligible, peak hardness being virtually the same after solution treatment at 1150 and $1200^{\circ} \mathrm{C}$, respectively. 
In general, these carbon-free tool steel grades offer attractive properties e.g. as cutting tool materials, being more stable against thermal softening than carbidic tool steels which is a definite advantage e.g. for machining of stainless steels or $\mathrm{Ti}$ alloys. The lower-Co variant does not offer hardness levels similar to high speed steels but rather those of cold work tool steels. This latter material seems to be particularly well suited for high-precision cold work tool steels, due to the virtually distortion-free hardening process. In the as-quenched state, both materials are fairly soft, the hardness being typically $<40 \mathrm{HRC}$, and thus can be soft machining and worked at room temperature. Hardening through aging is a fairly slow and isothermal process that results in very slight shrinkage, and since there are virtually no temperature gradients and no phase transformations, the shrinkage occurs in a very regular and predictable way, thus having only a negligible effect on geometrical precision. Compared to carbidic HSS, the need for hard machining or grinding processes is thus significantly reduced.

\section{Conclusions}

Carbon-free precipitation-hardenable steels of the general composition Fe-Co-Mo alloys can be obtained to advantage by powder metallurgy techniques, e.g. from elemental starting powders which are commercially available in very consistent quality as fine grades $<10 \mu \mathrm{m}$. Production involves mixing, axial or cold isostatic pressing, and sintering at suitably high temperatures. For the steel Fe-25\%Co, $15 \% \mathrm{Mo}, \mathrm{T}>1350^{\circ} \mathrm{C}$ is necessary while $\mathrm{Fe}-20 \%-\mathrm{Co}-15 \% \mathrm{Mo}$ is more tolerant regarding the temperature, also lower temperatures resulting in virtually full density. The last remaining pores are eliminated by hot working, e.g. by rolling, with resulting beneficial effect on the mechanical properties.

Heat treatment is done by solution annealing, quenching and artificial aging. Solution treatment should be carried out at a temperature at which only small amounts of the larger $\mu$-phases remain. In the fully aged condition, about $65 \mathrm{HRC}$ are attained for the higher Co level and about $62 \mathrm{HRC}$ for the lower Co grade, with a 3-point bending strength in the range 2000-2500 MPa. Here, once more the lower-Co grade FCM2 is more tolerant regarding the sintering temperature.

From the practical viewpoint, the Co-rich grade FCM1 is to be used if very high (hot) hardness is required, as e.g. for cutting of such metals that result in thermal overaging of the edge, as e.g. stainless steels or Ti alloys. Grade
FCM2, in contrast, seems to be well suited for cold work applications. In this case not so much the low tendency to overaging is attractive but rather the chance to carry out the heat treatment with minimum distortion, which is a distinct advantage of these steel grades compared to conventional carbidic tool steels.

\section{Acknowledgments}

This work was carried out within the Materials Center Leoben (MCL) and was financially supported by the Austrian Government through the $K_{\text {plus }}$ initiative.

\section{References}

[1] A.M.Bayer, L.R.Walton, in: ASM Handbook-Properties and Selection: Irons, Steels, and High-Performance Alloys, Vol. 1, 10th edition, ASM International, Materials Park OH 1990.

[2] G. Roberts, G. Krauss, R. Kennedy, Tool Steels, ASM, Materials Park, OH 1998.

[3] H.F. Fischmeister, S. Karagöz, Met. Trans. 29A, 205 (1998).

[4] W. Köster, W. Tonn, Arch. Eisenhüttenwesen 5, 431 (1932).

[5] W. Köster, W. Tonn, Arch. Eisenhüttenwesen 5, 627 (1932).

[6] W. Köster, Arch. Eisenhüttenwesen 6, 17 (1932).

[7] Ju.A. Geller, Instrumentalniye Staly, Metallurgia Publ., Moscow 1983.

[8] W.A. Brostrem, Ju.A. Geller, Metallowedeniye i termicheskaya obrabotka metallov 11, 35 (1966).

[9] W.A. Brostrem, Ju.A. Geller: Metallowedeniye i termicheskaya obrabotka metallov 1, 35 (1970).

[10] C. Harold, PhD Thesis, TU Vienna 2002.

[11] W. Köster, Lecture at the 75th birthday of R. Kieffer (1980).

[12] M.I. Karpov, et al., Proc. Powder Metall. World Congress 1998 Granada, EPMA ed., Shrewsbury 1998, vol. 3, p. 519.

[13] H. Danninger, F. Rouzbahani, Ch. Harold, H. Ponemayr, M. Daxelmüller, F. Simančík, K. Iždinský, Heat Treatment and Properties of Precipitation Hardened Carbon-Free PM Tool Steels, Powder Metall. Progress 5, 92 (2005).

[14] G.V. Raynor, V.G. Rivlin, Phase Equilibria in Iron Ternary Alloys, The Inst. of Metals, London 1988.

[15] H.H. Hausner, K.H. Mal, Handbook of Powder Metallurgy, Chemical Publ. Co. Inc., New York N.Y. 1982.

[16] E. Eidenberger, E. Stergar, H. Leitner, C. Scheu, P. Staron, H. Clemens, Precipitates in a $\mathrm{Fe}-\mathrm{Co}-\mathrm{Mo} \mathrm{Al}$ loy Characterized by Complementary Methods, Bergund Huettenmaenn. Monatshefte Vol. 153, 2008 p. 247. 